\title{
FROM SHELTER TO COMMUNITY RECOVERY: A RESEARCH PROJECT ON AN SAE AREA
}

\author{
CLAUDIA DELLA VALLE \& VINCENZO ROMANIA \\ Department of Philosophy, Sociology, Education and Applied Psychology, University of Padua, Italy
}

\begin{abstract}
Disastrous events raise issues about the territories and the affected population's future. Providing adequate housing for displaced people is both a challenge and a crucial point for any post-disaster policy. In this paper we will focus on the effects of long-term permanent housing solutions on displaced people. Anticipated data consist of the research we have conducted previously on the emergency housing solutions destined for displaced people from the Central Italy earthquake of 2016 who could not leave the territory. In our paper, we will briefly introduce the methodology and first results of our ongoing research, which extends the one we conducted in the earthquake area. Through ethnographic methodological tools and some interviews with actors involved in the emergency process, our main objective is to explore how the models of social interaction are reproduced and transformed in SAE areas. Small and medium-sized villages consist of single-family and earthquake-resistant houses, which will offer housing to the displaced population until the end of the reconstruction. We look forward to understanding how the brand new forms of settlement and social aggregation will affect the reconfiguration of social bonds. The new housing solutions push people to experience more frequent face-to-face interaction and with the challenge of community recovery. Then, the research intends to investigate whether, and how, the community recovery can lead to the formation of social capital and how it can be configured as a significant element capable of affecting the adaptive abilities, therefore resilient, of individuals, families and local community.
\end{abstract}

Keywords: qualitative disaster research, social capital, community, recovery, temporary housing, ethnography, Central Italy earthquake.

\section{INTRODUCTION}

Although in recent years interest in the topic of disasters has grown considerably and specific study paradigms have developed, the issue of what is meant by disaster and what physical, ecological or social events should be referred to, has long been difficult to clarify [1]. In the field of social sciences, scholars now agree that disasters should be considered as a social phenomenon, observable over time and through space; it disrupts the daily activities of social entities, which implement unplanned adaptive actions. Attention is no longer dedicated to the event or to the impact, but to the ways in which disasters interact with vulnerabilities, as weaknesses inscribed in the social structure [2], [3]; they derive from well-established social, political and economic processes that condition the manner and the intensity with which people are exposed to the disaster, and react to it [4]. The disaster, therefore, does not passively involve individuals but is socially constructed and actively implemented, through practices and processes of social interaction that take place at an individual, family, community and institutional level [1].

The post-disaster phase involves a variety of actors, both institutional and other types, who are called upon to respond to the challenge of recovery. In it, the importance of interactions and social ties is now widely recognized, but it must be supported by adequate post-emergency choices, in particular, concerning the housing dimension. The focus of this research is on the relationship between community, place and recovery process, in the hope that it can contribute to critical reflection on the importance of putting the community at the centre of the post-disaster phase. 


\section{THEORETICAL FRAMEWORK}

Beyond the breaking of normal social systems, the destruction of places and, sometimes, of human lives, disasters often involve the loss of houses. As a place of refuge and protection, the house must be a central point in the action of governments that, following a disaster, are required to provide a rapid and effective response to this need. Major international agencies dealing with emergency management, such as the United Nations High Commissioner for Refugees (UNHCR), the United Nations Human Settlements Program (UN-HABITAT) or the International Federation of Red Cross and the Red Crescent Societies (IFRC) consider the right to post-disaster accommodation related to the more general right of individuals to adequate housing, as enshrined in Article 25 of the Universal Declaration of Human Rights or in Article 11 of the International Convention on Economic, Social and Cultural Rights (ICESCR) [5]. Despite its recognized centrality, the topic of housing has become an integral part of disaster research only very recently.

Quarantelli [6], [7] identifies four typologies of post-disaster accommodation. The first one is emergency sheltering, i.e. those places where displaced people find shelter for a short time, usually for a few hours after the disaster. These are often spontaneous solutions, arising from immediate needs, and can include schools, gyms, churches, airports or any other building available for the first reception of the population. The second category, temporary shelter, indicates the spaces that offer temporary hospitality to the displaced people, once the first period of the emergency has passed. These solutions, which certainly require more planning than previous ones, are not limited to offering an emergency shelter but allow a whole series of individual daily needs to be satisfied: usually thought of as mass interventions, they provide shelter to the affected population, guarantee the distribution of water and food and the circulation of information. The resumption of daily activities and family responsibilities marks the difference between sheltering and housing. All those accommodations that allow a first, albeit temporary, restoration of domestic routines refer to temporary housing. The inhabitants are aware that this type of housing goes beyond the emergency and can extend for weeks and months, if not years. These solutions are characterized by a certain ambivalence: on the one hand they represent a significant improvement of the housing conditions for some individuals, on the other they could contribute to slowing down or inhibiting the search for a definitive home. Finally, permanent housing is defined as the condition of those who return to live permanently in their homes, following restoration work, or in new homes. The four typologies proposed do not always develop in a linear way, but they are configured as a social process that is not static; moreover, the differences between them are very often not so well-defined [6]-[8].

The restoration of housing is fundamental for the recovery process, at the individual, family, company or community level; the recovery of permanent housing allows individuals to restore and carry out normal domestic and daily activities. Delays in housing assignments very often lead to slowdowns in many of the other recovery dimensions [8]. For these reasons, the primary objective of the institutions should be to give the population the possibility of regaining ownership of their family habits and domestic routines following the disaster. This restitution of the "normal" everyday life can only happen through correct and careful planning of the new housing, or an adequate restoration of the old one, with the full knowledge that they can have a positive impact on displaced populations [9]. On the other hand, incorrect or careless planning can generate negative effects: in some cases, for example, long-term housing problems, determined by particular urban-architectural choices, may be related to the increase of pathologies triggered by disorientation processes, loss of the sense of place or they can create mechanisms that reproduce pre-existing structural vulnerabilities [10]. 
The destruction of material and human capital is given a lot of attention by multiple studies on disasters, widely supported by media coverage: the destroyed houses, the collapsed buildings, the rubble or the search and rescue phases of the population are shown. Less attention is often dedicated to social capital, because it is less tangible and more difficult to represent in the media. However, among all forms of capital, it is less damaged and less affected by the disaster; on the contrary, during the various phases of the emergency it is renewed and rapidly strengthened [11].

Theories of social capital refer to a multiplicity of definitions, given its complex and multidimensional nature. Although this article will not reconstruct the wider debate on the subject, it is beneficial to distinguish between a structural, relational or micro approach and a collective, community or macro approach [12]. The former sees social capital as an individual resource and focuses on the individual relations and social network; from the processes of social interaction it is possible to obtain gains and advantages [13] and achieve objectives [14], [15]. From a macro perspective, in contrast, social capital is as a public and collective resource, which facilitates the well-being of a community. Robert Putnam, one of the most authoritative exponents of this approach, writes that social capital refers to "features of social organizations, such as networks, norms, and trust, that facilitate coordination and cooperation for mutual benefit" [16, p. 35]. The author distinguishes between bonding social capital, which characterizes strong exclusive ties and strengthens solidarity and belonging in the group, and bridging social capital, which is more inclusive, is identified with the weakest ties, and which generates wider identities and reciprocity, including outside the group [17]. Some recent works in disaster research identify a third type of social capital, the linking one, which describes the relationships of trust between citizens and institutions. They also show that social capital positively affects all phases of the disaster: mitigation and adaptation, preparation and evacuation, response and impact, recovery [12], [18]-[20]. In this last phase, in particular, social capital plays a central role, both for individuals and families as well as for the communities, especially when state interventions are slow or non-existent.

According to Aldrich [18] and Aldrich and Meyer [19], the role of social capital is highlighted by three main mechanisms, through which networks can influence, and accelerate, the recovery process. Firstly, social ties can act as "informal insurance", offering subjects help and economic, logistical, psychological and emotional support. Secondly, the social capital is also linked to a more effective collective action, which allows greater participation in the dialogue with the authority, increasing the chances of satisfying the requests and needs. Finally, it hinders the strategy of exit, which consists of the abandonment of the affected communities by individuals, through an increase in the social cost. Thus, it is more likely that the population, through the strategy of voice, works collectively to overcome the crisis. From an interdisciplinary perspective, Spokane et al. [21] suggest that social capital should also be taken into account in the design of temporary houses, so as to facilitate short and long-term recovery process, especially for more vulnerable groups. The authors encourage the adoption of a synergistic or eco-systemic vision in the reconstruction of the community, possible only when the emergency physical structures are designed with attention placed on social and cultural networks.

However, some studies point to the ambivalent dimension of social capital in the disaster recovery process. Buckland and Rahman [22], for example, affirm that although it favours cooperation, fuelled by mutual trust, social capital can lead to a greater conflict in the decision-making process, due to the horizontal social structure that it promotes. Despite this, social capital is now considered as a key resource for communities, on a par with education, work, safety and health [12]. It also has a central role in a new perspective, called Community-Based Disaster Management: promoting a bottom-up approach to implementing 
emergency policies, while not undermining the institutions, local communities are supported in the analysis process and in raising their awareness of their own risk conditions, vulnerability and capacity, in order to respond promptly and flexibly to the disaster [23], [24].

The sociological literature suggests some dimensions on which to analyse social capital, for example, interpersonal trust, social cohesion, quality and density of ties and networks, associations and citizen participation. In order to investigate social capital in relation to the disaster and the recovery process, Minamoto [25] identifies three categories of indicators: the social norms, the behaviours and the attitudes of people during reconstruction; the characteristics of the organizations in the community and, finally, the changes in networks during the reconstruction. However, social capital, when not referring to a specific "object", should from time to time be interpreted in relation to the actors, the context and the aims that the research intends to pursue. Thus, it is a "situational and dynamic concept" [26, p. 395].

\section{CASE STUDY: THE CENTRAL ITALY EARTHQUAKE}

The case that we will analyse in this research is particularly suitable for exploring the dynamics of social capital that we have just discussed. We will study, in particular, the temporary houses assigned to the population following the seismic events that struck central Italy between August 2016 and January 2017. It was a complex situation, unprecedented in Italian history because of the territorial and the temporal extent of the disaster. A very large area, involving four distinct regions, was affected for a relatively long time. The earthquake affected some internal areas of the central Apennines: those areas are significantly far from the large and medium urban centres, as well as from the main poles of essential services, which have important environmental and cultural resources and constitute a profoundly diversified territory, the result of the dynamics of natural systems and of age-old processes of anthropization [27]. Like the Italian mountains, the internal areas of the central Apennines are subject to progressive depopulation and an aging population [28].

This territorial peculiarity is accompanied by an equally particular form of emergency management that is unprecedented in Italian history. Following the earthquake of 24th August 2016, which claimed 299 lives and resulted in around 12,500 damaged buildings, the institutions set up 43 tent camps and, at the same time, prepared for the reception of the population in habitable structures in the territory. From the beginning, however, Fabrizio Curcio, then head of the Civil Protection Department, underlined the intention to quickly dismantle the tent camps and identified some alternative housing solutions, contained in the Ordinance of the Head of the Civil Protection Department, 19th September 2016 n. 394: the granting of the autonomous accommodation contribution (CAS), the hospitality in public and hotel structures and the use of empty or second homes.

The seismic events of 26th and 30th October 2016 and of 18th January 2017, together with the worsening meteorological conditions, considerably complicated the scenario: there were another 34 fatalities; the so-called seismic crater expanded, including 140 municipalities; the number of damaged buildings increased, as well as the number of displaced persons, now reaching about 50,000. In addition to the housing assistance measures already provided for as a result of the first earthquake, the institutions added the Collective Housing Modules (MAC): temporary modular containers, consisting of accommodation modules with a maximum of three beds each, connected to shared toilets and collective spaces, such as refectories and living rooms. The MACs were installed in nine municipalities between Umbria and Marche, with a total of 23 residential settlements and 1,746 beds; moreover, they differed in size, hosting around 21 to 400 people. The MACs were to be considered as local temporary solutions, for those citizens with specific and urgent needs related, for example, to their work activity. In a previous study, Della Valle [29] further 
explored this solution, showing its limits and criticalities in terms of habitability. In addition to highlighting the fact that the most vulnerable population converged in the MACs, the research showed that the concept of comfort seemed to be absent, particularly in terms of its psychological-environmental meaning, which considers it as that "condition, belonging to and sought after in - everyday life, from which the uncertainty and the unexpected are expelled" [30, p. 104]. The housing dimension, more than any other area of everyday life, should represent this variation of comfort, just because the house "is above all the place of the known, of the familiar, as opposed to the external world" [30, p. 104]. Thus, it is possible to highlight that the MAC areas, on the contrary, were characterized by dynamics that are not only foreign to the sphere of comfort but that even amplified the uncertainty, the unpredictability and the precariousness of the population that lived there. The experiences of hardship and suffering experienced by the population, the feeling of being forgotten by the institutions, the uncertainty about the future, the impossibility of regaining their domestic habits and their autonomy, among other things, cause us to reflect on whether MACs can actually be considered housing; indeed, they have certain characteristics that are more related to shelter.

The housing solutions briefly outlined so far represent the institutional responses offered to the population in the phase of the first post-earthquake emergency, which should include the removal of the rubble, the reopening of the disaster zones and the conclusion of the light reconstruction, thereby allowing those who have suffered non-structural damage to return to their homes. In order to guarantee long-term accommodation, however, for citizens with destroyed or severely damaged homes, or those located in the disaster zone, there are Emergency Housing Solutions (SAE), which were the subject of a European tender proposal by the Department of Protection Civil in April 2014 and awarded in August 2015. The tender involved the supply, transport and assembly of prefabricated anti-seismic housing units, which will host the population until the end of the reconstruction. Each housing unit was installed in settlements of variable sizes, whose aggregate layout was left to the discretion of the contracted company, as well as the choice of the types of module foundations and urbanization works. Although the tender provided for the possibility of two-storey solutions, the companies decided to install single-family and single-storey housing units; this, together with the absence of prescriptions guaranteeing the effective temporary nature of the modules, suggests a lack of attention on behalf of the institutions regarding the territorial impact of these structures, which were built according to the standards of permanent constructions, often compromising the local territory [31].

Although the Civil Protection Department stated that the realization of the SAE would take about seven months, only 1,054 out of 3,702 orders were delivered in October 2017, corresponding to $28.5 \%$ of the total [32]. After about two years from the first earthquake, the data published on 17th August 2018 show that 3,639 SAEs out of 3,857 ordered, 94.3\%, have been completed [33].

\section{RESEARCH QUESTION AND METHODS}

Within such a scenario characterized by uncertainty and prolonged waiting, it is interesting to investigate how the inhabitants of temporary houses reproduce and modify their models of social interaction and how they perceive the living space that has been assigned to them, taking into account of the heterogeneity between the current settlements and the original context in which people lived. The physical environment is made up of objects, as the product of social interaction, that individuals and groups know and recognize, through an attribution of meaning. In order to understand how the actors develop their actions, therefore, it is essential on the one hand to identify the objects that make up the environment in which they 
live and act, and on the other hand to explore how this is perceived by the individuals, through a continuous formation and interpersonal transmission of meanings [34].

The assumption of this perspective, which recognizes the environment not as a passive substrate of human interaction but as an element with an active function, capable of conditioning action and producing territorial singularities [35], lays the foundations for a socio-territorial community study, focusing on the ways in which new housing configurations influence social ties and the possibility that they promote, or inhibit, the formation of social capital. Since the second half of the 20th century, the long sociological tradition of community studies has offered multiple, important contributions, among which Middletown by Lynd and Lynd [36]; Marienthal: The Sociography of an Unemployed Community, by Jahoda et al. [37]; Street Corner Society by Whyte [38]; The Moral Basis of a Backward Society by Banfield [39] or The Levittowners, written by Gans [40]. Although 20th century community studies have lost importance in today's scientific landscape, due to the lack of a precise definition of the research object and of a strong theoretical apparatus to refer to, it is possible to recognize a renewed vitality of this trend of studies. This is only possible if it is accepted, as an essential prerequisite, that the community does not constitute a fact, a homogeneous social group lived to a specific space, but rather an "object of a social construction by cooperating, competing or even conflicting actors" [35, p. 73], "a stake, or the outcome of a process that involves the project activity of a multiplicity of actors" [35, $p$. 79].

The approach that we want to support, in addition to recognizing the centrality of the community in the emergency and post-emergency phase, as suggested by Community-Based Disaster Management approach [23], [24], takes up a typical concept of the Chicago School, according to which social organization is configured not as a fact, but as a process. In a famous work, first published in 1918, Thomas and Znaniecki [41] develop the theory of social organization, within ecological theory, which underlines this procedural character. Conceiving society as being in perpetual change, the authors indicate three moments that belong to the continuous cycle of social life: social organization, social disorganization and social reorganization [42].

The characteristics of the research question, consistent with classical community studies, require a qualitative methodological approach, able to better understand the interactions and subjective interpretations of individuals and groups living in SAE areas. In particular, it was decided to refer to a SAE settlement whose housing units have been assigned to some citizens residing in a municipality of the Marche hinterland, which has few inhabitants but has an area of $78 \mathrm{~km}^{2}$ in the province of Macerata. This choice is due to the fact that the sociodemographic, territorial and economic characteristics of the municipality, while reflecting the general tendencies of the internal areas of central Italy, present peculiar aspects, compared not only to national averages, but also to those of the other municipalities in the seismic crater. Of particular interest is the fragmentation of the municipal area, which has particular characteristics in terms of types of inhabited locality. They can be divided into three different categories: the inhabited centre, characterized by the presence of contiguous or nearby houses with interposed public services, constituting the condition for an autonomous form of social life; the inhabited nucleus, that is, an aggregate of houses, with at least five families, even if they neighbour each other, however, they do not constitute a place of social aggregation due to a lack of public services; the scattered houses, which are scattered across the municipal territory over such a distance that they cannot form an inhabited nucleus [43]. Before the disaster, the largest proportion of the population residing in the municipality (44.1\%) lived in scattered houses, which represents $39.9 \%$ of total residential properties. This data is particularly significant if compared with the housing situation in the areas of the seismic 
crater. In fact, of all the population affected by the earthquakes, only $12.7 \%$ lived in scattered houses, which represent $16.8 \%$ of the residential buildings used. The difference is even more marked if compared to the national average data: the scattered houses represent $12 \%$ of the residential buildings inhabited, in which only $6 \%$ of Italians live [44].

In order to understand the dynamics preceding the disastrous event, the research will use second level data relating to the housing and territorial situation preceding the disaster, together with biographical interviews with some inhabitants of the SAE area. The ethnographic method, on the other hand, which combines observation, participation and dialogue, will allow us to explore in greater depth the context where social interaction usually takes shape, that is, in the SAE area [45]. Ethnographic notes and interviews represent the empirical material through which we will attempt to answer the research question, within the framework of the theory of argumentation. The qualitative methodological framework is also consistent with that widely used in Disaster Research, as an independent field of academic studies that was formalized in the 1960s with the foundation at the Ohio State University of the Disaster Research Center, the first research centre dealing with the study of disasters from a sociological perspective. The pioneering study by Prince in 1920 [46], the research conducted by the scholars of the National Opinion Research Center and of the Disaster Research Center, as well as those of the most recent research centres, share a marked sensitivity to qualitative methods. Indeed, they are better able to grasp the complexity of individuals and communities, which change rapidly and unexpectedly following a disaster. Qualitative Disaster Research, although often highlighting problems and inadequacies, such as an uneven use of data collection techniques or a lack of longitudinal research, can give voice to individuals and develop processes of individual and community empowerment [47].

\section{FROM SHELTERING TO HOUSING: AN ETHNOGRAPHY IN THE SAE AREA}

The results presented derive from the first phase of field exploration, consisting of three distinct ethnographic days. This indispensable phase of the research aims to achieve two complementary and interconnected objectives: on the one hand, the understanding of a sphere of social life that is foreign to the researcher; on the other, the possibility of developing and refining research in such a way that data and interpretations arise and remain rooted in the empirical context of study [34].

The SAE settlement was built in a flat agricultural area owned by the municipality, not far from the provincial road, near which there are some commercial activities. The SAEs were delivered to the mayor, then to the population, in December 2017, 16 months after the first earthquake and more than a year after the October 2016 shocks, which had a devastating effect on this territory, forcing most of the population to permanently abandon their homes. After the earthquakes of 26th and 30th October 2016, the mayor arranged for the first reception of the citizens, including many of the inhabitants of the SAE area, in the municipal hostel, the only public structure remaining accessible in the municipal territory. The temporary shelter identified by the mayor in place of the tent camps consisted of dormitories, each of which housed about 10 people, shared bathrooms and a common refreshment area. Volunteers from some local associations distributed the three daily meals for free.

From the stories of inhabitants it emerged that this first emergency phase represented a very difficult moment: in addition to the fear and desperation due to the events suffered, critical issues emerged regarding the overcrowding of the dormitories and the difficult balance between the schedules of the hostel and the daily and working life of individuals. In a short time, therefore, many of them chose alternative housing solutions. Some preferred those provided by the institutions, such as the CAS, public contributions with which to rent a house, or hospitality in hotels present on the territory or along the Adriatic coast. 
Alternatively, others have implemented informal housing solutions, being able to count on the support of family or friendship networks. The mayor, who at first identified two areas in which to place Collective Housing Modules (MAC), decided not to install them. Pending the assignment of the SAE, in this municipality, as in many other affected places, the housing solutions adopted by the population were different, mainly depending on the varying possibilities and resources, therefore on the different forms of capital (economic, social and cultural) [14], of each individual or family. For some, the assignment of the SAE represented the possibility of returning to their territory of origin; for others, the opportunity to regain their own, albeit precarious, domestic autonomy. Overall, it is possible to affirm that the assignment of SAEs has constituted, for the earthquake-affected population, the transition from shelter to housing, as conceptualized by Quarantelli [6], [7].

The housing settlement in question consists of 19 SAEs, in which about 60 individuals live, the majority of whom were known only superficially or not known at all before the assignment. The housing units are distributed on two small parallel streets, each three metres wide, which span out from the car park adjacent to the area. In each street, the SAEs are arranged opposite each other, at a distance of six metres. The aggregation layout chosen by the construction company is defined as "terraced": it provides for the contiguous distribution of the housing units, leaving two free fronts (Fig. 1). They present a standard structure, imposed by the technical specifications of the European tender issued by the Civil Protection Department, but differ in size, according to the number of household members: typology A, of $40 \mathrm{~m}^{2}$, is composed of a kitchen/living room, a bathroom and a bedroom and is intended for families of one or two members; typology B, of $60 \mathrm{~m}^{2}$, has a second room, used to accommodate families of three or four individuals; finally, typology $\mathrm{C}$ is $80 \mathrm{~m}^{2}$, it has three bedrooms and is intended for families of five or six people. In front of each SAE there is a covered outdoor area, a veranda, to ensure shelter from the sun and rain, designed as an extension of the living area and where tables and chairs are placed.

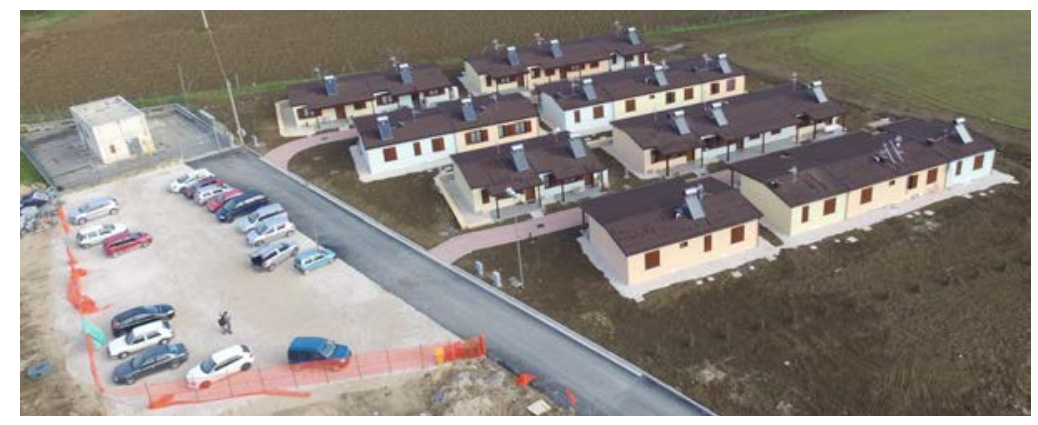

Figure 1: Photo of the SAE area. (Source: Website Marche Region.)

From a first exploration of the field it emerged that the demographic structure of the SAE settlement reproduces, at least in part, that of the municipality before the disaster. According to Istat data from July 2016, the population was 3,479 inhabitants, of which $9.5 \%$ foreigners. The demographic structure of the municipality showed a certain weakness, linked both to the incidence on the territory of people over $65(29.6 \%)$ and to the limited presence of young people $(10.5 \%)$, which results in a rather high old age index: 281.7 against 210.6 of the seismic crater municipalities and 161.4 of the Italian average. Furthermore, the low generational turnover is accompanied by a higher structural dependence, as the ratio between 
the non-active and working age population, equal to 66.8 compared to 59.6 of the seismic crater municipalities and 55.5 of Italy [44].

Similarly, in the SAE area there is a prevalence of elderly inhabitants, living alone or in pairs, and a limited number of households with children. Foreign families, on the other hand, are overrepresented, because they live in about one SAE out of three. The interesting question is that they, almost in their totality, were assigned SAEs located in one of the two streets of the housing settlement. The result is a strong ecological division of the area, which influences the forms and ways through which the inhabitants interact with each other. In fact, the inhabitants of each street are more likely to interact with their neighbours and minimise social contact with the other individuals in the settlement. If compared to a much larger scale, like the reality of a big metropolis, this is what probably some sociologists of the Chicago School, including Park [48], would have called natural areas, characterized by a certain degree of socio-cultural homogeneity that promotes interpersonal knowledge and, often, the creation of ties of solidarity. However, as Castrignanò [49] points out, in areas of study that are territorially and numerically smaller, as in the case of the SAE area, it is more appropriate to refer to urban interstices (buildings, condominiums, street crossings or small streets) or to "non-public collective spaces", meaning, for example, courtyards and walkways inside buildings but outside homes, "able to act as incubators to establishment of relationships, with a high 'recognition coefficient' that allows rooting in a known and familiar environment" [50, p. 203].

In the SAE area, each street often turns into a place of meeting and socializing; the veranda of each house, under which individuals, especially the older ones, sit and spend a good part of the day, becoming the privileged observation point over what is happening, but also the prevailing communicative space, given the spatial proximity between the housing units. This aspect, if related to the pre-disaster housing situation, is very interesting. Individuals have, in fact, passed from an extremely disaggregated mountain-housing context, characterized by a considerable presence of scattered houses, to an aggregated context, similar to that which can be found in the city. Informal interviews with some inhabitants show an increase in the perception of security related to this new housing configuration. Individuals can now count on the help and support of others if something happens, such as a new earthquake. Some have pointed out that it is sufficient to raise their tone of voice to be heard by neighbours, unlike the situation in their previous homes. Others have said that they willingly sacrificed some features of mountain life, being in contact with nature, in exchange for the advantage of the spatial and social proximity they now have. Experiencing the dramatic event of the earthquake, and the subsequent emergency phase, has certainly upset them but, at the same time, it has brought them closer. Within each street, in fact, individuals can count on the help and goodwill of neighbours. There is no lack of reciprocal exchanges of small daily favours, such as shopping or borrowing something; sometimes there is even the creation of fiduciary and solidarity ties demonstrated, for example, by the possibility that some inhabitants entrust their children to neighbours for a short period of time.

\section{CONCLUSIONS}

In conclusion, the exploration phase of the SAE area has revealed some important elements, to be further explored during the research. Among these, there is certainly the perception, by the inhabitants, of both the individual living space and the non-public collective spaces [50]; the modalities of assigning SAEs by the institutions, in an attempt to understand the reasons underlying the ecological division of the settlement; the creation and reproduction of social capital, bridging, bonding or linking, within the two streets that compose the SAE area, in order to reflect on the role of the community in the recovery process. Finally, reading the 
disaster with the conceptual triad proposed by Thomas and Znaniecki [41], the exploratory phase has brought out an interesting suggestion, which will certainly be explored further later. Just as the disaster would mark the passage from a phase of social organization to one of social disorganization, the assignment of SAEs, or the transition from shelter to housing, would allow a first social reorganization, which, in the post-recovery phase, would stabilize into a new social organization. This, in line with what has been argued in the theoretical part, could have repercussions on exit routes and strategies, especially for the most vulnerable individuals. While not considering these as linear and orderly moments, but being characterized by fluidity and dynamism, the result is a circular reading of the disaster, which actively involves communities and territories, during a continuous process, from the predisaster phase to post-recovery one.

\section{REFERENCES}

[1] Ligi, G., Antropologia dei disastri, Laterza: Roma, 2009.

[2] Perry, R.W., Defining disaster: An evolving concept. Handbook of Disaster Research, eds H. Rodríguez, W. Donner \& J.E. Trainor, Springer: Cham, pp. 3-22, 2018.

[3] Quarantelli, E.L., A social science research agenda for disasters of the 21st century: Theoretical, methodological and empirical issues and their professional implementation. What is a Disaster: New Answers to Old Questions, eds R.W. Perry \& E.L. Quarantelli, Xlibris Publishers: Philadelphia, pp. 325-396, 2005.

[4] Wisner, B., Blaikie, P., Cannon, T. \& Davis, I., At Risk: Natural Hazards, People's Vulnerability, and Disaster, Routledge: London, 2004.

[5] Bennicelli Pasqualis, M., Case Temporanee. Strategie Innovative per L'emergenza Abitativa Post Terremoto, Franco Angeli: Milan, 2014.

[6] Quarantelli, E.L., General and particular observations on sheltering and housing in American disasters. Disasters, 6(4), pp. 277-281, 1982.

[7] Quarantelli, E.L., Patterns of sheltering and housing in US disasters. Disaster Prevention and Management: An International Journal, 4(3), pp. 43-53, 1995.

[8] Peacock, W.G., Dash, N., Zhang, Y. \& Van Zandt, S., Post-disaster sheltering, temporary housing and permanent housing recovery. Handbook of Disaster Research, eds H. Rodríguez, W. Donner \& J.E. Trainor, Springer: Cham, pp. 569-594, 2018.

[9] Corsellis, T. \& Vitale A., Transitional Settlement, Displaced Populations, Oxfam: Oxford, 2005.

[10] Ciccozzi, A., I pericoli della ricostruzione: antropologia dell'abitare e rischio sociosanitario nel dopo-terremoto aquilano. Epidemiologia \& Prevenzione, 40(2), pp. 93-97, 2016.

[11] Dynes, R.R., Community Social Capital as the Primary Basis for Resilience. Disaster Research Center, University of Delaware, Preliminary paper 344, 2005.

[12] Meyer, M.A., Social capital in disaster research. Handbook of Disaster Research, eds H. Rodríguez, W. Donner \& J.E. Trainor, Springer: Cham, pp. 265-286, 2018.

[13] Lin, N., Social Capital: A Theory of Social Structure and Action, Cambridge University Press: New York, 2001.

[14] Bourdieu, P., The forms of capital. Handbook of Theory and Research for the Sociology of Education, ed. J.G Richardson, Greenwood: New York, pp. 241-258, 1986.

[15] Coleman, J.S., Foundations of Social Theory, Belknap Press: Cambridge and London, 1990. 
[16] Putnam, R.D., The prosperous community: Social capital and public life. The American Prospect, 4(13). 1993. http://prospect.org/article/prosperous-communitysocial-capital-and-public-life. Accessed on: 5 May 2019.

[17] Putnam, R.D., Thinking about social change in America. Bowling Alone. The Collapse and Revival of American Community, ed. R.D. Putnam, Simon \& Schuster: New York, pp. 12-27, 2000.

[18] Aldrich, D.P., Social capital in post disaster recovery: Towards a resilient and compassionate East Asian community. Economic and Welfare Impacts of Disasters in East Asia and Policy Responses, eds Y. Sawada \& S. Oum, ERIA: Jakarta, pp. 157178, 2012.

[19] Aldrich, D.P. \& Meyer, M.A., Social capital and community resilience. American Behavioral Scientist, 59(2), pp. 254-269, 2015.

[20] Hawkins, R.L. \& Maurer, K., Bonding, bridging and linking: How social capital operated in New Orleans following Hurricane Katrina. British Journal of Social Work, 40, pp. 1777-1793, 2010.

[21] Spokane, A.R., Mori, Y. \& Martinez, F., Housing arrays following disasters: Social vulnerability considerations in designing transitional communities. Environment and Behavior, 45(7), pp. 887-911, 2013.

[22] Buckland, J. \& Rahman, M., Community-based disaster management during the 1997 Red River Flood in Canada. Disasters, 23(2), pp. 174-191, 1999.

[23] Allen, K.M., Community-based disaster preparedness and climate adaptation: Local capacity-building in the Philippines. Disasters, 30(1), pp. 81-101, 2006.

[24] Pandey, B. \& Okazaki, K., Community based disaster management: Empowering communities to cope with disaster risks. United Nations Centre for Regional Development, Japan, 2012.

http://citeseerx.ist.psu.edu/viewdoc/download?doi=10.1.1.467.1932\&rep=rep1\&type $=$ pdf. Accessed on: 5 May 2019.

[25] Minamoto, Y., Social capital and livelihood recovery: Post-tsunami Sri Lanka as a case. Disaster Prevention and Management, 19(5), pp. 548-564, 2010.

[26] Piselli, F., Capitale sociale: Un concetto situazionale e dinamico. Stato e mercato, $\mathbf{3}$, pp. 395-417, 1999.

[27] Barca, F., Casavola, P. \& Lucatelli, S., Strategia nazionale per le Aree interne: Definizione, obiettivi, strumenti e governance. Materiali Uval, 31, 2014.

[28] Fondazione Montagne Italia, Rapporto Montagne Italia 2016. www.dropbox.com/s/f76iz9bmebgx32c/RAPPORTO\%20MONTAGNE\%20ITALIA STAMPA.pdf?dl=0. Accessed on: 5 May 2019.

[29] Della Valle, C., Con-vivere con il terremoto. Il sisma dell'Appennino Centrale e le soluzione-container nelle Regioni Umbria e Marche, Masters thesis, University of Bologna, 2018.

[30] Marrone, V., La costruzione sociale dell'efficienza energetica. Un approccio sistemico a CasaClima. Sociologia Urbana e Rurale, 114, pp. 95-112, 2017.

[31] Emidio di Treviri, Sul fronte del sisma. Un'inchiesta militante sul post-terremoto dell'Appennino centrale (2016-2017), DeriveApprodi: Roma, 2018.

[32] Terremoto Centro Italia, i numeri dell'emergenza a un anno dalle scosse del 26 e 30 ottobre. Dipartimento della Protezione Civile - Presidenza del Consiglio dei Ministri. www.protezionecivile.gov.it/media-comunicazione/comunicati-stampa/dettaglio//asset_publisher/default/content/terremoto-centro-italia-i-numeri-dell-emergenza-aun-anno-dalle-scosse-del-26-e-del-30-ottobre. Accessed on: 5 May 2019. 
[33] Dipartimento della Protezione Civile - Presidenza del Consiglio dei Ministri, I numeri del sisma in Centro Italia. www.protezionecivile.gov.it/resources/cms/documents/ Aggiornamento_dati_Terremoto_Centro_Italia.pdf. Accessed on: 5 Mar. 2019.

[34] Blumer, H., Symbolic Interactionism. Perspective and Method, University of California Press: Englewood Cliffs, 1969.

[35] Mela, A., Per una nuova generazione di studi di comunità. Sociologia Urbana e Rurale, 110, pp. 71-85, 2016.

[36] Lynd, R.S. \& Lynd, H.M., Middletown: A Study in American Culture, Harcourt, Brace and World: New York, 1965.

[37] Jahoda, M., Lazarsfeld, P.F. \& Zeisel, H., Marienthal: The Sociography of an Unemployed Community, Tavistock: London, 1972.

[38] Whyte, W.F., Street Corner Society: The Social Structure of an Italian Slum, University of Chicago Press: Chicago, 1943.

[39] Banfield, E.C., The Moral Basis of a Backward Society, The Free Press: Illinois, 1958.

[40] Gans, H.J., The Levittowners: Ways of Life and Politics in a New Suburban Community, Pantheon Books: New York, 1967.

[41] Thomas, W.I. \& Znaniecki, F., The Polish Peasant in Europe and America, Alfred A. Knopf: New York, 1927.

[42] Romania, V., La Scuola di Chicago e la sua eredità. Lezioni Italiane. L'eredità Della Scuola di Chicago, ed. V. Romania, Orthotes: Napoli and Salerno, pp. 41-71, 2018.

[43] Glossario Istat, http://dawinci.istat.it/daWinci/jsp/MD/misc.jsp?p=7._Accessed on: 16 May 2019.

[44] Caratteristiche dei territori colpiti dal sisma del 24 agosto, 26 ottobre e 30 ottobre 2016 e 18 gennaio 2017, Istat. www.istat.it/it/archivio/199364. Accessed on: 5 May 2019.

[45] Cardano, M., La Ricerca Qualitativa, Il Mulino: Bologna, 2011.

[46] Prince, S.H., Catastrophe and Social Change. Based upon a Sociologic Study of the Halifax Disaster, Columbia University Press: New York, 1920.

[47] Phillips, B., Qualitative methods and disaster research. International Journal of Mass Emergencies and Disaster, 15(1), pp. 179-195, 1997.

[48] Park, R.E., Human Communities: The City and Human Ecology, The Free Press: Glencoe, IL, 1952.

[49] Castrignanò, M., Il concetto di comunità: quale spendibilità per la sociologia urbana? Sociologia Urbana e Rurale, 88, pp. 73-88, 2009.

[50] Micheli, G.A., "Vis resistiva": Come indurre a ridefinire lo spazio-azione dell'anziano, Le sfide dell'esclusione: metodi, luoghi, soggetti, ed. E. Mingione, Il Mulino: Bologna, pp. 197-217, 1999. 